\title{
Presence of generalized periodic discharges and hospital mortality
}

\author{
Presença de descargas periódicas generalizadas e mortalidade hospitalar \\ Larissa MIYASHIRO', Carolina OLIVEIRA DE PAULO', Carlos Alexandre TWARDOWSCHY'
}

\begin{abstract}
Background: Generalized periodic discharges (GPDs) are rare patterns that can be found in long-term electroencephalographic monitoring in critical patients. These patterns have been correlated with non-seizure crisis and non-convulsive status epilepticus, associated with poor prognosis. Objective: To compare the outcome between patients who developed GPDs and patients with other abnormalities in long-term electroencephalographic monitoring. Methods: A retrospective study was performed by analyzing the medical records of 112 patients over 18 years who developed GPDs during long-term electroencephalographic monitoring (12-16 hours of monitoring) in the intensive care unit of a general hospital, compared with a group that had only nonspecific abnormalities in the monitoring. Results: Age and cardiorespiratory arrest (CA) were risk factors for death - OR $1.04(95 \% \mathrm{Cl} 1,02-1,07)$ and $p<0.001$; OR $3.00(95 \% \mathrm{Cl} 1,01-8,92)$ and $p=0.046$, respectively. It was not possible to evaluate if GPDs alone were associated with an unfavorable outcome or would be a bias for the development of CA in these patients. However, of the six isolated GPDs cases, 2/3 evolved to death, showing a tendency to worse prognosis. A significant difference $(p=0.031)$ was observed for a worse outcome when comparing the group of 28 patients who presented GPD or CA with the other group which did not present any of these variables; of these 28 patients, 20 (71.4\%) died. Conclusions: The presence of post-CA GPDs was associated with worse prognosis, but it was not clear whether these patterns are independent factors of an unfavorable evolution.
\end{abstract}

Keywords: Electroencephalography; Intensive Care Units; Encephalopathies; Hospital mortality.

\section{RESUMO}

Introdução: As descargas periódicas generalizadas (DPG) são padrões raros que podem ser encontrados durante monitorização eletroencefalográfica prolongada (MEP) em pacientes críticos. Esses padrões têm sido correlacionados com crises não convulsivas e estado de mal epiléptico não convulsivo, associados a um pior prognóstico. Objetivo: Comparar o desfecho entre pacientes que desenvolveram DPG e pacientes com anormalidades inespecíficas na MEP. Métodos: Foi realizado um estudo retrospectivo através da análise dos prontuários de 112 pacientes acima de 18 anos que desenvolveram DPG durante MEP (de 12-16 horas de monitorização) na unidade de terapia intensiva de um hospital geral, comparando com um grupo que apresentou apenas anormalidades inespecíficas na MEP. Resultados: As variáveis idade e parada cardiorrespiratória (PCR) se mostraram como fatores de risco estatisticamente significativos para óbito - OR 1,04 (IC 95\% 1,02 - 1,07) e p<0,001; OR 3,00 (IC 95\% 1,01 - 8,92) e p=0,046, respectivamente. Não foi possível avaliar se DPG isoladamente se associaram a um desfecho desfavorável ou seriam um viés para o desenvolvimento de PCR nesses pacientes. Porém, dos seis casos de DPG isoladas, 2/3 evoluíram para óbito, o que revela uma tendência a pior prognóstico. Foi observada diferença significativa $(p=0,031)$ para pior desfecho ao comparar o grupo de 28 pacientes que apresentou DPG ou PCR com o outro grupo que não apresentou nenhuma dessas variáveis, sendo que desses 28 pacientes, 20 (71,4\%) foram a óbito. Conclusões: A presença de DPG pós-PCR está associada a pior prognóstico, porém não ficou claro se esses padrões são fatores independentes de evolução desfavorável.

Palavras-chave: Eletroencefalografia; Unidades de Terapia Intensiva; Encefalopatias; Mortalidade hospitalar.

\section{INTRODUCTION}

Generalized periodic discharges (GPDs) are rare patterns that can be found during long-term electroencephalographic monitoring, but relatively common in comatose patients after cardiorespiratory arrest $(\mathrm{CA})^{1,2,3,4,5}$. They are defined as synchronous, bihemispheric, and repetitive discharges of similar morphology with quantifiable, almost regular intervals between them ${ }^{6}$. These patterns have been associated with significant functional impairment and adverse clinical outcomes, resulting in a high mortality rate, which may range from 30 to $64 \%^{1,2,7}$.

GPDs were highly related to non-convulsive seizures and non-convulsive status epilepticus (NCSE), which have been

${ }^{1}$ Pontifícia Universidade Católica do Paraná, Hospital Universitário Cajuru, Curitiba, Paraná, Brazil.

Larissa MIYASHIRO (iD https://orcid.org/0000-0002-2684-0572; Carolina OLIVEIRA DE PAULO (iD https://orcid.org/0000-0001-6893-5484;

Carlos Alexandre TWARDOWSCHY (iD) https://orcid.org/0000-0003-3667-0412

Correspondence: Larissa Miyashiro; E-mail: larissa_Imm@hotmail.com

Conflict of interest: There is no conflict of interest to declare.

Received on September 19, 2019; Received in its final form on January 21, 2020; Accepted on February $19,2020$. 
strongly associated with a worse prognosis ${ }^{3,5,8}$. NCSE consists of electrographic seizures lasting at least 30 minutes that, in addition to non-convulsive seizures, can be detected on the electroencephalogram (EEG) of comatose patients. It is believed that the presence of these findings may worsen the patient's recovery or cause clinical deterioration, even with the appropriate treatment of the primary cause of coma ${ }^{9,10}$. In the study performed by Ruijter et al., patients with good results showed early improvement to a continuous EEG background pattern before the development of $\mathrm{NCSE}^{8}$. This seems to be the key to recovery from post-anoxic encephalopathy, also observed in other studies ${ }^{11,12}$. The outcome was unfavorable when NCSE developed within the first 36 hours after CA (period when temperature management and associated sedative medication occurs) and when preceded by surge suppression ${ }^{4,8}$.

Patients with GPDs tend to have epileptic seizures later, with the first seizure occurring within 24 hours of EEG onset ${ }^{8}$, and within 48 hours of discharge detection ${ }^{4}$. Factors of poor prognosis are prolonged duration and use of more than two antiepileptic drugs to suppress the seizure, association with myoclonus, more suppression, lower discharge frequency, and higher periodicity of discharges ${ }^{8}$.

Regarding the bad prognosis to which the presence of GPDs could be associated, some studies have observed death of most patients within the first month after visualization of these patterns in the EEG, with cerebral hypoxic-ischemic injury being the major cause of morbidity and mortality $^{1,4,13,14}$. For surviving patients, studies revealed a high degree of impaired sequelae of consciousness and unfavorable clinical conditions in all patients with GPDs ${ }^{4}$, and only a $12-14 \%$ probability of independent recovery ${ }^{2}$. One study showed that GPDs were the only EEG factors related to the NCSE outcome and are associated with worse outcome regardless of etiology ${ }^{15}$. However, although these studies indicate a worse outcome for patients with GPDs, Foreman et al. research finding was that independent factors associated with poor prognosis are coma, cardiac arrest, sepsis, cancer, and NCSE 3 .

The aim of this study was to investigate the outcome of patients who already developed GPDs in the intensive care unit of a university hospital in Brazil, and comparing with a group of patients with nonspecific abnormalities in longterm electroencephalographic monitoring.

\section{METHODS}

The research was conducted in the intensive care unit at Cajuru University Hospital of Curitiba, Paraná, Brazil. This was a retrospective study that analyzed the medical records of patients aged over 18 years who were submitted to long-term electroencephalographic monitoring (12-16 hours) at some time in the intensive care unit, between October 2017 and December 2018. Among these patients, we separated those who developed GPD, according to the criteria of the American Clinical Neurophysiology Society's Standardized Critical Care EEG Terminology: 2012 version $^{6}$, and compared with the other patients that presented any other abnormality in the long-term electroencephalographic monitoring (non-GPDs abnormalities group). The non-GPDs group included patients with: polyspikes, spikes, LPDs (lateralized periodic discharges), GRDA (generalized rhythmic delta activity), nearly continuous with attenuation, nearly continuous with suppression, burst suppression, and suppression. The following data were collected: age, gender, category of presenting illness, outcome (discharge or death), NCSE (yes / no), post-arrest (yes / no). Incomplete medical records and patients transferred to another hospital due to loss of outcome were excluded. The patients submitted to this procedure were not approached for this project, being exclusively an analysis of medical records, valuing the anonymity and confidentiality of the collected information. The project was approved by the institution ethics committee. Data were stored in Microsoft Word and Microsoft Excel programs for statistical analysis. The results were presented by Epi-Info 7 and correlated with the literature.

The results of quantitative variables were described by means, standard deviations, and minimum and maximum values. For categorical variables, frequencies and percentages were presented. Univariate analysis of factors associated with outcome (favorable or dead) was performed using Student's t-test for independent samples (age) or Fisher's exact test (categorical variables). For the multivariate analysis, a logistic regression model was adjusted. The Wald test was considered for decision making regarding the significance of the variables and the estimated association measure was the odds ratio. Values of $\mathrm{p}<0.05$ indicated statistical significance. Data were analyzed using the computer program Stata / SE v.14.1. StataCorpLP, USA.

\section{RESULTS}

The following analysis was performed based on data from 112 patients. The comparison between the different variables and their respective outcomes was performed (Table 1). The category of presenting illness is illustrated in Figure 1. The NCSE variable was strongly associated with the presence of GPDs, since all patients with GPDs had NCSE at some point of the long-term electroencephalographic monitoring.

Of the 112 patients, 71 were men and 41 women, with death occurring in 49.3 and $61.0 \%$ respectively. The average age of patients with favorable outcomes was 47.3 years, while patients who died had a mean age of 60.6 years. The most common etiology for GPDs was hypoxic encephalopathy, followed by trauma and intracranial hemorrhage.

Analyzing only the GPD variable, nine cases were observed, whereas seven (77.8\%) died and two (22.2\%) had a 
favorable outcome $(\mathrm{p}=0.172)$. Seventeen patients had NCSE, of whom 13 (76.5\%) died. For patients who did not develop this variable, a balance was found between favorable (50.5\%) and unfavorable $(49.5 \%)$ outcomes $(\mathrm{p}=0.063)$. Similarly, patients without CA had a balanced outcome between favorable (51.1\%) and death (48.9\%), while the 22 patients with CA had a more expressive percentage of deaths $(72.7 \%)$ than favorable outcomes $(27.3 \%)(\mathrm{p}=0.057)$.

Besides the trends, there was a significant difference $(\mathrm{p}=0.031)$ when comparing the group of patients who presented GPD or CA with the other group that did not present any of these variables. Of the 28 patients who presented one of the two variables, 20 (71.4\%) died, while of the 84 patients who did not have GPD or CA, 40 (47.6\%) died.

Analyzing the GPD and post-CA variables in all their possible combinations, of the six patients who presented GPD alone, four (66.7\%) died. Likewise, 13 (68.4\%) out of the 19 patients who had isolated CA died. Only three patients had concomitant GPD and CA, and all of them had unfavorable outcomes.

In Table 2, when analyzing only the variables age and post-CA, both were associated with the increased probability

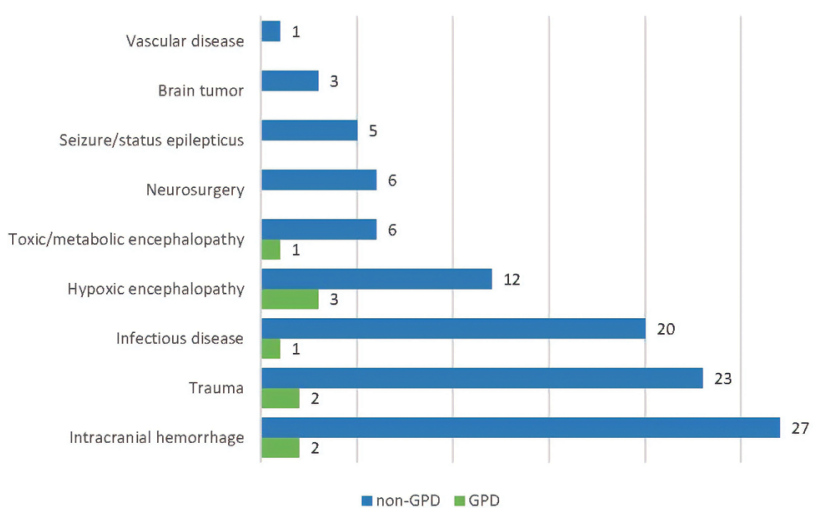

Figure 1. Category of presenting illness.

Table 2. Association between age, post cardiorespiratory arrest and probability of death.

\begin{tabular}{lcc}
\hline Variable & $p$-value* & OR (95\%Cl) \\
\hline Age (years) & $<0.001$ & $1.04(1.02-1.07)$ \\
Post-cardiac arrest & 0.046 & $3.00(1.01-8.92)$ \\
\hline
\end{tabular}

OR: Odds Ratio; 95\%Cl: 95\% confidence interval.

Table 1. Comparison between variables and its outcomes.

\begin{tabular}{|c|c|c|c|c|c|}
\hline \multirow{2}{*}{ Variable } & \multirow{2}{*}{ Classification } & \multirow{2}{*}{$\mathrm{n}$} & \multicolumn{2}{|c|}{ Outcome } & \multirow{2}{*}{$p$-value* } \\
\hline & & & Favorable $(n=52)$ & Death $(n=60)$ & \\
\hline Age (years) & & & $47.3 \pm 19.6(18-86)$ & $60.6 \pm 16.0(22-90)$ & $<0.001$ \\
\hline \multirow{2}{*}{ Sex } & Male & 71 & $36(50.7)$ & $35(49.3)$ & \\
\hline & Female & 41 & $16(39.0)$ & $25(61.0)$ & 0.246 \\
\hline \multirow{2}{*}{ GPD } & No & 103 & $50(48.5)$ & $53(51.5)$ & \\
\hline & Yes & 9 & $2(22.2)$ & $7(77.8)$ & 0.172 \\
\hline \multirow{2}{*}{ Status epilepticus } & No & 95 & $48(50.5)$ & $47(49.5)$ & \\
\hline & Yes & 17 & $4(23.5)$ & $13(76.5)$ & 0.063 \\
\hline \multirow{2}{*}{ Post-arrest } & No & 90 & $46(51.1)$ & $44(48.9)$ & \\
\hline & Yes & 22 & $6(27.3)$ & $16(72.7)$ & 0.057 \\
\hline \multirow{4}{*}{ GPD and status epilepticus } & No and No & 95 & $48(50.5)$ & $47(49.5)$ & \\
\hline & Yes and No & 0 & - & - & \\
\hline & No and Yes & 8 & $2(25.0)$ & $6(75.0)$ & \\
\hline & Yes and Yes & 9 & $2(22.2)$ & $7(77.8)$ & - \\
\hline \multirow{2}{*}{ GPD and status epilepticus } & Others & 95 & $48(50.5)$ & $47(49.5)$ & \\
\hline & Yes and Yes & 17 & $4(23.5)$ & $13(76.5)$ & 0.063 \\
\hline \multirow{4}{*}{ GPD and Post-cardiac arrest } & No and No & 84 & $44(52.4)$ & $40(47.6)$ & \\
\hline & Yes and No & 6 & 2 (33.3) & $4(66.7)$ & \\
\hline & No and Yes & 19 & $6(31.6)$ & $13(68.4)$ & \\
\hline & Yes and Yes & 3 & $0(0)$ & $3(100)$ & - \\
\hline \multirow{2}{*}{ GPD and Post-cardiac arrest } & Others & 84 & $44(52.4)$ & $40(47.6)$ & \\
\hline & GPD and/or Cardiac Arrest & 28 & $8(28.6)$ & $20(71.4)$ & 0.031 \\
\hline
\end{tabular}

*Student's t-test (age); Fisher's exact test (categorical variables); $p<0.05$. 
of death. The odds ratio for age was 1.04 (95\% confidence interval [95\% CI] 1.02-1.07; $\mathrm{p}<0.001)$; for the post-arrest variable the odds ratio was 3.00 (95\%CI 1.01-8.92; $\mathrm{p}=0.046$ ).

\section{DISCUSSION}

In the present study, only nine cases of GPDs were identified, whereas seven $(77.8 \%)$ died. The sample size limited the statistical analysis of this variable; however, it is still possible to perceive a tendency $(\mathrm{p}=0.172)$ that these electroencephalographic patterns are factors for an unfavorable outcome.

Foreman et al. conducted a retrospective study with 200 critically ill patients with GPDs, in which $27 \%$ had nonepileptic seizures and $22 \%$ developed NCSE. The authors' initial hypothesis was that GPDs would be associated with crisis, mainly non-seizures, and related to a bad prognosis. The strong relationship between non-convulsive seizures and NCSE seizure with GPDs was consistent with their hypothesis, but came to the conclusion that only the disease state was an independent factor of an unfavorable outcome, but not GPDs. Nevertheless, they believe that a small association is still possible 3 . In our study, we observed that patients with CA or NCSE had a higher death rate, characterizing possible risk factors for a worse outcome. Due to the small sample size, we observed only unfavorable outcome trends $(\mathrm{p}=0.057$ for CA and 0.063 for NCSE). When these variables were not present, patients were almost as likely to progress to a favorable as unfavorable outcome.

With an incidence of approximately $1-5 \%$ in most studies, GPDs may be present in about $20 \%$ of patients with hypoxic or anoxic injury following $\mathrm{CA}^{2,3,16,17,18}$. Previous studies shows that GPDs may occur in many disease states, such as hypoxic-ischemic encephalopathy, metabolic and infectious disease, medication toxicity, non-convulsive status epilepticus ${ }^{3,4,5}$. In our sample, the most common etiology for GPDs was hypoxic encephalopathy, followed by trauma and intracranial hemorrhage.

As it has been observed in several studies that CA is a poor prognostic factor ${ }^{3,11}$, we attempted to perform a statistical calculation by analyzing CA and GPDs alone, together and absence of both, to assess whether isolated GPDs are considered risk factors for poor prognosis or would be a bias (CA increasing mortality in patients with GPDs) in those patients with both conditions. Unfortunately, due to the large number of variables and the small number of patients, it was not possible to perform a statistical analysis. However, it is possible to observe that of the six cases of isolated GPDs in this study, $2 / 3$ died. If the sample number were increased, we could enlighten if the presence of isolated GPDs could translate into an unfavorable evolution or if it is a merely marker. The study by Li and colleagues identified some clinical features that may be associated with GPDs and contribute to the increased risk of an unfavorable outcome. These factors include age $>65$ years, systemic disease, anoxic encephalopathy, NCSE, and some drug toxicities, such as the antibiotics cefepime and meropenem. This could explain why, although most GPD patients have a poor prognosis, some may still have a positive outcome $e^{2}$. Table 2 of this study only analyzed the variables age and post-CA, and both proved to be statistically significant risk factors for death. No other variables were added, as the small number of patients could invalidate the evaluation.

When the patients with GPDs or CA were divided into 4 categories, there was too many variables and not enough patients to lead to statistical significance. Therefore, we divided these patients into two groups: one with GPDs or post-CA and another without these conditions. This allowed us to obtain one statistically significant result ( $\mathrm{p}=0.031$ ), which showed a worse outcome when patients had GPDs or CA compared to other patients. Besides that, we can suggest that the presence of GPDs and / or CA is a major risk factor for worse outcome, because even in a limited sample size, we had a statistically significant result. The detection of these electroencephalographic patterns and the knowledge of their significance in relation to the prognosis is important so that the proper management of the patients is possible and so we acquire the ability to evaluate in what circumstances and with what intensity we should interfere. To Foreman et al., treating the underlying etiology and NCSE, as well as promoting careful monitoring, are the most important considerations in the care of patients with GPDs. Patients should undergo long-term electroencephalographic monitoring to identify the presence of a NCSE, which according to them is independently associated with a bad outcome in patients with and without GPDs. In addition, they believe that aggressive treatment of GPDs should be reserved for cases where there is evidence of ongoing neuronal injury or when there is a presence of NCSE defined based on EEG patterns or clinical features (3). Some authors use antiepileptic drugs to treat GPDs, but only a minority of epilepsy specialists treat GPD patients equally aggressively to those with clinically manifest NCSE. Other studies also reveal that the treatment of GPDs with antiepileptic drugs does not improve patient outcomes $^{18,19}$.

We suggest that the presence of GPDs after cardiorespiratory arrest can be related to an unfavorable outcome, but it was not clear whether these patterns during long-term electroencephalographic monitoring are independent factors of poor prognosis. It will be necessary to follow up the project in order to increase the sample number and to obtain significant results in comparisons where this was not possible. Besides the reduced sample, another limitation of this study was the short period of EEG monitoring (12-16h), which might lead to under-recognition of ictal-interictal activity. In addition, we could not be able to evaluate SOFA/APACHE scores or systemic derangements of the patients, as this information was not included in the medical records. 
1. San-Juan OD, Chiappa KH, Costello DJ, Cole AJ. Periodic epileptiform discharges in hypoxic encephalopathy: BiPLEDs and GPEDs as a poor prognosis for survival. Seizure. 2009 Jun;18(5):365-8. https:// doi.org/10.1016/j.seizure.2009.01.003

2. Li HT, Wu T, Lin WR, Tseng WEJ, Chang CW, Cheng MY, et al. Clinical correlation and prognostic implication of periodic EEG patterns: a cohort study. Epilepsy Res. 2017 Mar;131:44-50. https://doi. org/10.1016/j.eplepsyres.2017.02.004

3. Foreman B, Claassen J, Khaled KA, Jirsch J, Alschuler DM, Wittman $J$, et al. Generalized periodic discharges in the critically ill: a casecontrol study of 200 patients. Neurology. 2012 Nov;79(19):1951-60. https://doi.org/10.1212/WNL.0b013e3182735cd7

4. Yemisci M, Gurer G, Saygi S, Ciger A. Generalised periodic epileptiform discharges: clinical features, neuroradiological evaluation and prognosis in 37 adult patients. Seizure. 2003 Oct;12(7):465-72. https://doi.org/10.1016/s1059-1311(02)00351-5

5. Sully KE, Husain AM. Generalized periodic discharges : a topical review. J Clin Neurophysiol. 2018 May;35(3):199-207. https://doi. org/10.1097/WNP.0000000000000460

6. Hirsch LJ, Laroche SM, Gaspard N, Gerard E, Svoronos A, Herman ST, et al. American clinical neurophysiology society's standardized critical care EEG terminology: 2012 version. J Clin Neurophysiol. 2013 Feb;30(1):1-27. https://doi.org/10.1097/ WNP.0b013e3182784729.

7. Lewis DW, Johnson EL. Prognosis of periodic and rhythmic patterns in adult and pediatric populations. J Clin Neurophysiol. 2018 Jul;35(4):303-8. https://doi.org/10.1097/WNP.0000000000000442

8. Ruijter BJ, van Putten MJAM, Hofmeijer J. Generalized epileptiform discharges in postanoxic encephalopathy: quantitative characterization in relation to outcome. Epilepsia. 2015 Nov;56(11):1845-54. https://doi.org/10.1111/epi.13202

9. Banu SH. EEG in ICU: A monitoring tool for critically ill patient. Bangladesh Crit Care J. 2014 Ago;2(1):28-34. https://doi. org/10.3329/bccj.v2i1.19954

10. Claassen J, Mayer SA, Kowalski RG, Emerson RG, Hirsch LJ. Detection of electrographic seizures with continuous EEG monitoring in critically ill patients. Neurology. 2004 May;62(10):1743-8. https:// doi.org/10.1212/01.wnl.0000125184.88797.62

11. Lamartine Monteiro M, Taccone FS, Depondt C, Lamanna I, Gaspard $\mathrm{N}$, Ligot N, et al. The prognostic value of 48-h continuous EEG during therapeutic hypothermia after cardiac arrest. Neurocrit Care. 2016 Apr;24(2):153-62. https://doi.org/10.1007/s12028-015-0215-9

12. Rundgren M, Westhall E, Cronberg T, Rosén I, Friberg H. Continuous amplitude-integrated electroencephalogram predicts outcome in hypothermia-treated cardiac arrest patients. Crit Care Med. 2010 Sep;38(9):1838-44. https://doi.org/10.1097/CCM.0b013e3181eaa1e7

13. Ribeiro A, Singh R, Brunnhuber F. Clinical outcome of generalized periodic epileptiform discharges on first EEG in patients with hypoxic encephalopathy postcardiac arrest. Epilepsy Behav. 2015 Aug;49:268-72. http://dx.doi.org/10.1016/j.yebeh.2015.06.010

14. Renzel R, Baumann CR, Mothersill I, Poryazova R. Persistent generalized periodic discharges: A specific marker of fatal outcome in cerebral hypoxia. Clin Neurophysiol. 2017 Jan;128(1):147-52. http://dx.doi.org/10.1016/j.clinph.2016.10.091

15. Nei M, Lee JM, Shanker VL, Sperling MR. The EEG and prognosis in status epilepticus. Epilepsia. 1999 Feb;40(2):157-63. https://doi. org/10.1111/j.1528-1157.1999.tb02069.x

16. Koren JP, Herta J, Pirker S, Fürbass F, Hartmann M, Kluge T, et al. Rhythmic and periodic EEG patterns of 'ictal-interictal uncertainty' in critically ill neurological patients. Clin Neurophysiol. 2016 Feb;127(2):1176-1181. https://doi.org/10.1016/j.clinph.2015.09.135

17. Swisher CB, Shah D, Sinha SR, Husain AM. Baseline EEG pattern on continuous ICU EEG monitoring and incidence of seizures. J Clin Neurophysiol. 2015 Apr;32(2):147-51. https://doi.org/10.1097/ WNP.0000000000000157

18. van Putten MJAM, Hofmeijer J. Generalized periodic discharges: Pathophysiology and clinical considerations. Epilepsy Behav. 2015;49:228-33. http://dx.doi.org/10.1016/j.yebeh.2015.04.007

19. Tjepkema-Cloostermans MC, Hindriks R, Hofmeijer J, van Putten MJAM. Generalized periodic discharges after acute cerebral ischemia: reflection of selective synaptic failure? Clin Neurophysiol. 2014 Feb;125(2):255-62. http://dx.doi.org/10.1016/j.clinph.2013.08.005 